\title{
sciforum
}

\section{Study on Visceral Fat Area (VFA) and IVF-ET Assisted Pregnancy Outcomes}

\author{
Kun Liu ${ }^{a}$, César Martin Plagaro ${ }^{b}$, Bairong Shen ${ }^{c}$ \\ ${ }^{a}$ Reproductive Medicine Center of Lanzhou University First Hospital, Lanzhou, 730030, China \\ ${ }^{b}$ Biochemistry and Molecular Biology Department, University of the Basque Country UPV/EHU, \\ 48940, Leioa, Biscay, Spain. \\ ${ }^{C}$ Institutes for Systems Genetics, West China Hospital, Sichuan University, Chengdu, 610000, China
}

\section{Graphical Abstract}

None

\begin{abstract}
Objective To examine the effect of visceral fat area (VFA) on pregnancy outcomes in in vitro fertilization and embryo transfer (IVF-ET). Methods We performed a single-center prospective observational study using female infertility patients with normal ovarian reserve undergoing IVF-ET. Endocrine abnormalities and autoimmune disease were excluded. Participants were divided into three groups based on VFA composition: lean $\left(\mathrm{VFA} \leq 50 \mathrm{~cm}^{2}\right)$, normal $\left(50 \mathrm{~cm}^{2}<\mathrm{VFA} \leq 70 \mathrm{~cm}^{2}\right)$, and overweight (VFA> $70 \mathrm{~cm}^{2}$ ). Result There were statistically significant differences in infertility years $(\mathrm{P}=0.033)$, total ampules of gonadotropin used $(\mathrm{P}=$ $0.019)$, and clinical pregnancy rate $(\chi 2=396.0, \mathrm{P}$ $<0.001)$ in the three VFA groups. Infertility years and total ampules of gonadotropin used in the overweight group increased significantly as compared to lean and normal group. Clinical pregnancy rate decreased significantly with VFA reduction. However, there was no significant difference in down-regulation duration of Gonadotrophin-releasing hormone $(\mathrm{GnRH})$ agonists (GnRHa) ( $\mathrm{P}=0.762)$, total ampules of GnRHa ( $\mathrm{P}=$ $0.378)$, days of ovulation ( $\mathrm{P}=0.285), \mathrm{E}_{2}$ level on trigger day $(\mathrm{P}=0.130)$, number of eggs retrieved ( $\mathrm{P}$ $=0.953)$, two pronuclei $(2 \mathrm{PN})$ rate $(\mathrm{P}=0.415)$, and good-quality embryos $(\mathrm{P}=0.149)$. Conclusion $\mathrm{An}$
\end{abstract}


[Key word] Visceral Fat Area; In Vitro Fertilization and Embryo Transfer; Pregnancy Outcomes

\section{References}

[1] Mancini C, Gohlke S, Garcia-Carrizo F et al. Identification of biomarkers of brown adipose tissue aging highlights the role of dysfunctional energy and nucleotide metabolism pathways [J]. Sci Rep. 2021,11(1):19928.

[2] Jung SM, Sanchez-Gurmaches J, Guertin DA. Brown Adipose Tissue Development and Metabolism [J]. Handb Exp Pharmacol. 2019;251:3-36.

[3] Sharp LZ, Shinoda K, Ohno H, et al. Human BAT possesses molecular signatures that resemble beige/brite cells [J]. PLoS One,2012,7(11):e49452.

[4] Müller MJ, Lagerpusch M, Enderle J, et al. Beyond the body mass index: tracking body composition in the pathogenesis of obesity and the metabolic syndrome [J]. Obes Rev,2012,13(Suppl 2):6-13.

[5] Li X, Katashima M, Yasumasu T, et al. Visceral fat area, waist circumference and metabolic risk factors in abdominally obese Chinese adults [J]. Biomed Environ Sci,2012,25(2):141-148.

[6] Farhi J, Ben-Haroush A, Sapir O, et al. High-quality embryos retain their implatation capability in overweight women [J]. Reprod Biomed Online,2010,21(5):706-711.

[7] Zhang D,Zhu Y,Gao H,et al.Overweight and obesity negatively affect the outcomes of ovarian stimulation and in vitro fertilisation: acohort study of 2628 Chinese women [J]. Gynecol Endocrinol,2010,26(5):325-332.

[8] Boon MR, van Marken Lichtenbelt WD. Brown Adipose Tissue: A Human Perspective [J]. Handb Exp Pharmacol. 2016;233:301-319.

[9] Montanari T, Pošćić N, Colitti M. Factors involved in white-to-brown adipose tissue conversion and in thermogenesis: a review [J]. Obes Rev. 2017, 18(5):495-513. 